\title{
STRESS EFFECT ON CEMENTATION FACTOR OF SANDSTONE ROCKS TYPE EVIDENCE FOR A VARIABLE ARCHIE POROSITY EXPONENT "m"
}

\author{
Ali El-Aswad, Intesar Elagil and Salem Fatooh \\ Petroleum engineering department, Zawia university \\ alielaswed@gmail.com
}

\begin{abstract}
Ancient sandstones include important reservoirs for hydrocarbons (oil and gas). This research provides an experimental investigation on the influence of variations in confining pressure on cementation factor of two wells located in Sirt basin. Measurements of formation resistivity factor versus cementation factor for sandstone samples which were collected from both wells at different confining pressures were carried out. The Effects of confining stress on the electrical properties of the rock samples were studied and analyzed. The results showed that the confining pressure variations depend on the pore structure of the studied rock. Furthermore, it can be concluded that the electrical resistivity of rocks is function of pore size distribution and how the fluids were distributed in the pore spaces. The effect of overburden pressure and the porosity variation on cementation factor is also investigated for different rock types. It has been concluded that the compaction due to overburden pressure generally causes a considerable increase in resistivity, especially in poorly cemented rocks. In low-porosity rocks, resistivity measurements determined under representative overburden pressures that are strongly recommended to improve well $\log$ interpretation.
\end{abstract}

Keywords: cementation factor, formation resistivity factor, rock samples, porosity, confining pressures.

\section{Introduction}

The principal digenetic processes of sandstone are compaction and pressure solution, and silica and calcite cementation. In the initial stage, compaction involves dewatering and a closer packing in grains. Further compaction carried out through overburden pressure results in local fracturing and bending of weak grains and solution of grains at points of contact. Most sediment deposited under normal surface conditions has primary porosities of the order of $30 \%$ to $70 \%$. The lower values are more typical for coarser sandy sediments, and the higher initial porosities are more typical for finer-grained, clay-rich sediments. Porosity in conglomerates and sandstones largely depends on pore spaces and grains framework, as modified by 
later cementation together with certain other digenetic changes (The physical and chemical changes occurring in sediments between the times of deposition and solidification). Porosity in carbonate rocks varies widely, depending upon sediment type: the porosity of well-sorted carbonate sands is in the same general range as that of the corresponding silica clastic sands, whereas reef carbonates commonly have much higher initial porosities. Cementation Factor $(m)$ of rocks depends on their lithology, as shown in Table 1. The objectives of this research are studying the effect of overburden pressure on cementation factor in case of sandstone rocks, comparing between those effects on sandstone rocks and investigating the effect of porosity variation on cementation factor.

Table 1: Cementation Factor (m) and Lithology (Ching h.wu.,1992)

\begin{tabular}{|l|c|}
\hline \multicolumn{1}{|c|}{ Lithology } & m values \\
\hline Unconsolidated rocks (loose sand, oolitic limestones) & 1.3 \\
\hline Very slightly cemented (gulf coast type of sand, except Wilcox) & $1.4-1.5$ \\
\hline Slightly cemented (most sands with 20\%poroosity or more ) & $1.6-1.7$ \\
\hline Moderately cemented (highly consolidated sands of 15\% porosity or less) & $1.8-1.9$ \\
\hline Highly cemented (low-porosity sands, quartzite, limestone dolomite) & $20-22$ \\
\hline
\end{tabular}

\section{Basic concepts}

\section{Micro Log and Core Porosity}

It is a logging method that can provide formation factor at the well site. The device comprises a measuring system pressed against the wall of the borehole. The formation factor is independent of the electrical conductivity of the fluid in the pores. The porosity is obtained from the micro log curve and log header. A good petro physical interpretation involves developing core and well log interpretations using a calibration model (WJ Teh, GP Willhite, JH Doveton, JS Tsau ; 2011).

The core-measured porosity is integrated with well log interpreted formation resistivity factor to estimate reliable porosities. Then the variation of $\mathrm{m}$ in reference to its relationship with pore geometry is explained based on the classification method for sandstone reservoir rocks as an initial step to determine parameters for well log interpretation.

\section{Choice of Archie Equation}

Archie's law in its original form responds to rock geometry and pore network which is directly dependent on the inverse power of porosity with a cementation exponent, $\mathrm{m}$ that expressed as (Archie, G.E.; 1942).

$$
F=1 / \emptyset^{m}
$$


Where:

$$
\begin{aligned}
& \mathrm{F}=\text { Formation Resistivity Factor } \\
& \Phi=\text { Porosity } \\
& \mathrm{M}=\text { Cementation Exponent }
\end{aligned}
$$

Using a constant $\mathrm{m}$ value across broad rock types lead to large inaccuracies in petrophysical property determination (Rezaee,M.R., Motiei, H.\&Kazemzadeh, E2007;Gomez, C.T.,Dvorkin, J.\&Vanorio,T;2010). Various modifications to the Archie equation have been proposed (Haro,C;2010). Since the cementation exponent is based on the effect of rock fabric and pore throat attributes, we use the original form of Archie equation.

\section{Cementation Exponent or Shape Factor}

The modeling of heterogeneity in a reservoir is crucial to get an accurate estimate of water saturation, which is significant to hydrocarbon reserve calculation and production forecasting. In formation evaluation, the petrophysical properties of a particular formation rely on the assessment of the properties of the core samples and estimation of the Archie cementation exponent (m). However, the presence of complex pore networks and variable faces attributes such as particle size, sorting and type of porosity within a single rock faces influences the measured resistivity. Therefore, in a heterogeneous reservoir, the routine practice of using constant $\mathrm{m}$ values for a given reservoir rock is impractical. The cementation exponent $\mathrm{m}$ quantifies the electrical conductivity and permeability of a rock by accounting for its pore connectivity. But the cementation exponent $\mathrm{m}$ is not a constant as it is related to the rock variability in heterogeneous reservoirs. The cementation exponent is defined in terms of the effect of porosity and connectivity on the connectedness of the rock, where the connectedness is the formation conductivity (Glover,P;2009). Therefore, it is clear that the cementation exponent is indicative of the connectivity as well as the porosity of the rock fabric.

The cementation exponent is found to exhibit variations within the sample, formation, interval or medium. $\mathrm{m}$ has been reported to be slightly less than one for fractured rock and up to 3 for compacted sandstone. The cementation exponent is highly dependent on the type and shape of the pores and grains as opposed to tortuosity, specific surface area and anisotropy of the rock (Salem, H.S.\& Chilingarian, G.V.1999). Table 2 shows the reported $\mathrm{m}$ value for sandstone. 
Table 2: Archie's parameter m for the sandstone (Teh,GP Willhite, JH Doveton, JS Tsau 2011).

\begin{tabular}{|l|c|c|}
\hline Lithology & $\mathrm{m}$ & Investigator \\
\hline Unconsolidated sand & 1.3 & Archie (1942) \\
\hline Cemented sandstone & $1.8-2.0$ & Salem and Chilingarian (1999) \\
\hline Clean sand & $2.0-2.3$ & Gomez et al. (2010) \\
\hline Compacted sand & $1.8-3.0$ & \\
\hline Sandstone & $1.52-2.09$ & \\
\hline
\end{tabular}

\section{Effect of Overburden Pressure}

The porosity in sandstone has been found to have an exponentially decreasing trend with depth, which could be attributed to the effects of compaction and overburden pressure (Medina,C.R., Rupp,J.A.\&Barnes,D.A;2011). There are many factors affecting cementation factor such as porosity, pore throat size, type of rock grains, type and distribution of clay content, degree of cementation, and overburden pressure (SaeeRafiee,AbdolnabiHashemi,\&MohammadShahi;2014).

Increasing the overburden pressure deforms the rock grains and causes shrinkage in pore volume and also an increase in the resistivity. Therefore, the cementation factor increases at a higher overburden pressure. Most fine-grained sediments lose pore water soon after deposition by consolidation, the process by which clay-rich mud is changed to mudstone. This is largely a consequence of compaction due to overburden. There are many factors affect cementation factor, such as porosity, pore throat size, type of rock grains, type and distribution of clay content, degree of cementation and overburden pressure. Increasing the overburden pressure deforms the rock grains and causes shrinkage of pore volume and also increase of the resistivity. Therefore the cementation factor increases at higher overburden pressure.

\section{Ranges for the Cementation Factor}

Mathematically the cementation factor $(\mathrm{m})$ can vary from 1.0 to infinity. In practice, this factor ranges from 1.0 to 3.0. The values of $m=1.3$ in clean unconsolidated sands packed in the labo-ratory and that $\mathrm{m}$ falls in a range of 1.8 to 2.0 in consolidated sandstones. For non-touching Vug carbonates, the value of $(\mathrm{m})$ ranges from 1.8 to as high as 4 , while the $(\mathrm{m})$ value may be less than 1.8 in the presence of fractures (Myeres,M.1991). Values of $\mathrm{m}=3.0$ are found in non-connected molded porosity, whereas Values of $\mathrm{m}$ are less than 1.3 when there are fractures or non-uniform features in the void space which are favorably aligned in the direction of the current flow. Conventional wisdom suggests using $\mathrm{m}$ value of 2 when no other information is available. However, the resulting of water saturation will be too low if $(\mathrm{m})$ is smaller than 2, and too high if $\mathrm{m}$ is larger than 2 . By changing of the $(\mathrm{m})$ value from 2 to 3 the water saturation changes from $32 \%$ to $71 \%$ or from oil production to water 
productive(Lucia, F.J.2007). The factor $\mathrm{m}$ is related to the geometry imposed upon the bulk volume of interstitial water of both solid and fluid insulating materials. The cementation factor is strongly dependent on shape, surface area of composite particles and tortuosity. It has been given considerable attention by researchers, because of the various physical effects of cementation factor on the physical behavior of sediments. So, the cementation factor of the carbonate reservoir is the most important parameters for applying the petrophysical characterization (Hilmi S.Salem.1993\& Hector, P.,Fernando S.,Guadalupe,G.,Jesus R., Carlos V;2007).

\section{Methodology}

A group of core analyses were retrieved for two wells (S1, and S2), Table 3, from different well fields. The core data of 19 samples were collected from the both sandstone wells as: 11 , and 8 consequently, with porosity, permeability and Grain density measurements.

Table 3: Samples of the two sandstone wells

\begin{tabular}{|c|c|c|}
\hline No. & Well & Number of studied samples \\
\hline 1 & S1 & 11 ( out of 30) \\
\hline 2 & S2 & 8 \\
\hline$\sum$ & 2 & 19 \\
\hline
\end{tabular}

All the calculations in this work were done by using Excel sheets. The detailed information, procedures, and results obtained are tabulated and in figures described. Petroleum reservoir rocks are subjected to: Internal stresses exerted by fluid movement (gas, oil, and water) in the pore spaces, and external stresses exerted by the overlying rocks. So, petroleum reservoirs are considered as dynamic systems, due to variable fluids depleted from the pore spaces by well production. This depletion causes the change in the internal stress, and effects on the resultant stress of reservoir rock. By water flooding or gas injection, the equilibrium of rock stresses can be also altered in a dynamic manner.

\section{Samples preparation}

Moreover, while the sample is being brought to the surface, the confining pressure of the fluid column is constantly decreasing. This reduction permits the expansion of the entrapped water, oil and gas. Gas, having a greater coefficient of expansion, expels oil and water from the core. Thus, the fluid contents of the core at surface can be significantly different than those in the formation

(Amyx,W. A., Daniel M. B., and Robert, L.W.;1960) . The added value of a coring program in terms of reducing uncertainty in rock and fluid properties should be clearly indicated. The objective of coring and core analysis is to reduce uncertainty 
in reservoir evaluation by providing data representative of the reservoir at in situ conditions. The advances in coring and core analysis techniques provide the premise to measure required petro-physical properties and to acquire simultaneously other reservoir rock dependent parameters. Core derived data have been integrated with other field data to minimize reservoir uncertainties that cannot be addressed by other data sources such as well logging, well testing or seismic (C.E.Ubani,Y.B.Adeboye, A.B.Oriji; 2012).

\section{Bulk density, Porosity, and Permeability measurements}

\section{Bulk density calculation:}

Sandstone has been classified based on grain size, packing and sorting, and the cementation exponent of the rock. In general, the cementation exponent has been found to have an inverse relationship with the permeability of sandstone (Frailey,S.M.,Damico,J.\&Leetaru,H.E.2011). Used groupings of Archie's sandstone $\mathrm{m}$ to separate the porosity-permeability plot into zones characteristic of $\mathrm{m}$. Interrelationships have been developed between permeability, porosity, formation factor and parameters like tortuosity, which are representative of the pore structure of sandstone. The cementation exponent $\mathrm{m}$ quantifies the electrical conductivity and permeability of a rock by accounting for its pore connectivity. But the cementation exponent $\mathrm{m}$ is not a constant as it is related to the rock variability in heterogeneous reservoirs (Salem,H.S.\&Chilingarian,G.V. 1999). Overall, it has been observed that a majority of the variation in cementation exponent of sandstones can be explained based on porosity and permeability of the rock. Neutron logs are porosity logs that measure the hydrogen concentration in a formation. In clean formations (i.e., shalefree), where the pores are filled with water or oil, because hydrogen in a porous formation is concentrated in the fluid-filled pores, energy loss can be related to the formation porosity. Whenever shale is part of the formation matrix the reported neutron porosity is greater than the actual formation porosity. This occurs because the hydrogen that is within the shale's structure and in the water bound to the shale is sensed in addition to the hydrogen in the pore spaces (Antwan M. Avedisian.1988). The density tool responds to the electron density of the material in the formation. Formation bulk density $(\rho b)$ is a function of matrix density, porosity, and density of fluids in the pores (salt water, fresh water mud, or hydrocarbons). The formula for calculating density-derived porosity is (Schlumberger, 1989).

$$
\Phi d=\frac{\rho b_{\log }-\rho b_{m a}}{\rho b_{f}-\rho b_{m a}}
$$

Where:-

$\rho b m a=$ the matrix density, $[2.71 \mathrm{~g} / \mathrm{c} 3$ for limestone, $2.87 \mathrm{~g} / \mathrm{c} 3$ for dolomite and $2.65 \mathrm{~g} / \mathrm{c} 3$ for sandstone]. 
$\rho b f=$ the fluid density,g/c3 [fresh water $=1$, mud, for salt water mud 1.1]

At a given depth, the overburden pressure is the pressure exerted by the cumulative weight of the overlying sediments. The cumulative weight of the overlying rocks is a function of the bulk density, the combined weight of the matrix and formation fluids contained within the pore space. Overburden increases with depth, as bulk density increases and porosity decreases (Salem, H. S. \& Chilingarian, G. V, 1999) .

\section{Porosity calculation:}

A measure of the pore space available for the storage of fluids in rock. In general form:

$$
\Phi=\frac{V p}{V b}=\frac{(V b-V m)}{V b}
$$

where:-

$\Phi=$ porosity, fraction

$\mathrm{Vb}=\mathrm{Vp}+\mathrm{Vm},(\mathrm{L} 3)$

$\mathrm{Vb}=$ bulk volume of reservoir rock, (L3)

$\mathrm{Vp}=$ pore volume, $(\mathrm{L} 3)$

$\mathrm{Vm}=$ matrix volume, $(\mathrm{L} 3)$

\section{Permeability measurement:}

The permeability of the rock is a measure of the ease of convicting fluids through it and may be determined by a flow experiment. Permeability from logs, cores and cross plots have been derived and compared with permeability from well testing. Permeability from logs alone is derived and based on porosity and water saturation, porosity has been calculated from density log which is easily affected by the shape of well. Permeability from cores, gives a good overview of the permeability distribution in the cored interval, but is difficult to scale up for the un-cored interval. The Arithmetic scaling gives much higher values than the geometric method. The best permeability is from well testing; the effective permeability of the tested interval is calculated. All effects are counted for in the permeability, minerals and overburden pressure reduces the permeability. In many cases there may exist a correlation between porosity and permeability. But these correlations are usually derived for a certain formation. Therefore, they do not exhibit general application or validity. In heterogeneous carbonate reservoirs the cementation factor, $\mathrm{m}$, is a major factor of uncertainty in the calculation of hydrocarbon-water saturation. The following trends are given for the limestone cores and for permeability values (Salem, H. S. \& Chilingarian, G. V, 1999) :

$$
m=1.2+0.1286 \emptyset \ldots \ldots \ldots \ldots . .(77) \text { For } \mathrm{K}<0.1 \mathrm{md}
$$




$$
\begin{aligned}
& m=1.4+0.0857 \emptyset \ldots \ldots \ldots \ldots .(84) \text { For } \mathrm{K}=0.1 \text { to } 1 \mathrm{md} \\
& m=1.2+0.0829 \emptyset \ldots \ldots \ldots \ldots .(85) \text { For } \mathrm{K}=1 \text { to } 100 \mathrm{md} \\
& m=1.22+0.034 \emptyset \ldots \ldots \ldots . .(86) \text { For } \mathrm{K}>100 \mathrm{md}
\end{aligned}
$$

\section{Formation Resistivity factor at ambient conditions measurements:}

The resistance values were used to calculate specific resistivity (Ro) of the plug samples as following:

$$
\begin{aligned}
& F=\mathrm{Ro} / \mathrm{Rw} \text { at } 100 \% \text { water saturation } \\
& F=1 / \Phi \mathrm{m}
\end{aligned}
$$

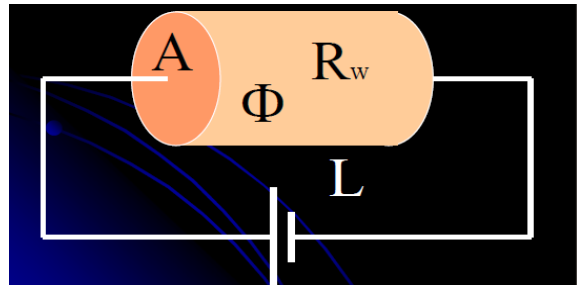

$$
R o=(\text { ro } * \mathrm{~A}) / \mathrm{L}
$$

Where :

Ro $=$ sample resistivity at $100 \%$ water saturation

ro $=$ resistance of rock at $100 \%$ water saturation (device reading)

$\mathrm{A}=$ sample Area

$\mathrm{L}=$ sample length

And the water resistivity is calculated by:

$$
\mathrm{Rw} @ 25 \mathrm{oC}=\mathrm{Rw} *(\mathrm{~T}+22) / 47 * 0.001
$$

\section{F- $\Phi$ Plot method:}

This method is used to calculate $\mathrm{m}$ from laboratory measurements as $\mathrm{F}$ can be measured in core full saturated with brine where:

$$
\mathrm{F}=\text { RoLab. } / \mathrm{Rw} \text { at } 100 \% \mathrm{Sw}
$$

and $\Phi$ is also can be measured laboratory for the same core or cab be taken form logs at the same depth of this core. The theoretical basis of this method depends on the relation between the formation factor and the porosity as shown in equation (1), which becomes with the use of logarithms:

$$
\mathrm{F}=\mathrm{a} / \emptyset_{\mathrm{m}}
$$

Logarithm distribution

$\log \mathrm{F}=\log \mathrm{a}-(-\mathrm{mlog} \Phi)$ 


$$
\begin{aligned}
& \log \mathrm{F}=\mathrm{m} \log \Phi \\
& \mathrm{m}(\text { Exponent })=\log \mathrm{F} / \log \Phi
\end{aligned}
$$

\section{Data, Results, and Discussions:}

Petrophysical properties such as porosity, permeability, capillary pressure, resistivity, and relative permeability are influenced by the state of stress acting on the rock. These properties should be measured at a stress state that resembles the in situ stress. Therefore, core analyses on petrophysical properties at different confining pressures (depths) are carried out. Electrical resistivity is generally dependent on the geometry of the pore space and its fluids. The reservoir rock pore space is normally occupied by: gas, oil, and water. Gas and oil are nonconductors, while water is the only conductive fluid if it contains dissolved salts. Two sandstone wells are considered here under investigation. 11 samples are taken from the S1-well, 8 samples from the S2. The depth in which the samples were collected is represented in table 4 and figures1 and 2.

Table 4:Smples collected depth

\begin{tabular}{|l|l|l|l|}
\hline well & Depth & Formation & Number of sample \\
\hline S1 & $12565-12664$ & Nubian sandstone & $11 \quad$ (out of 30) \\
\hline S2 & $8188-8235$ & Harash and sabil & 08 \\
\hline
\end{tabular}

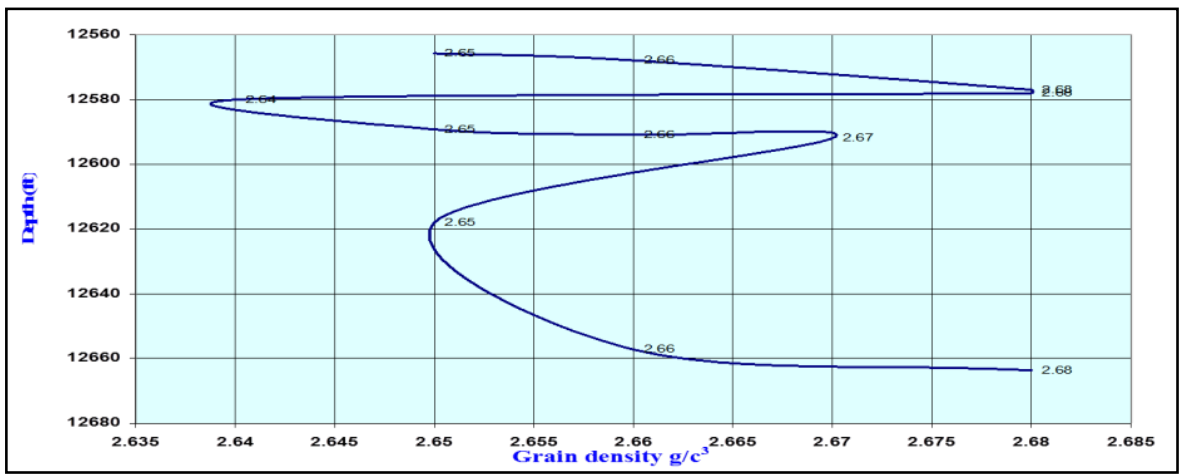

Figure1: Effect of depth on Grain density for well S1. 


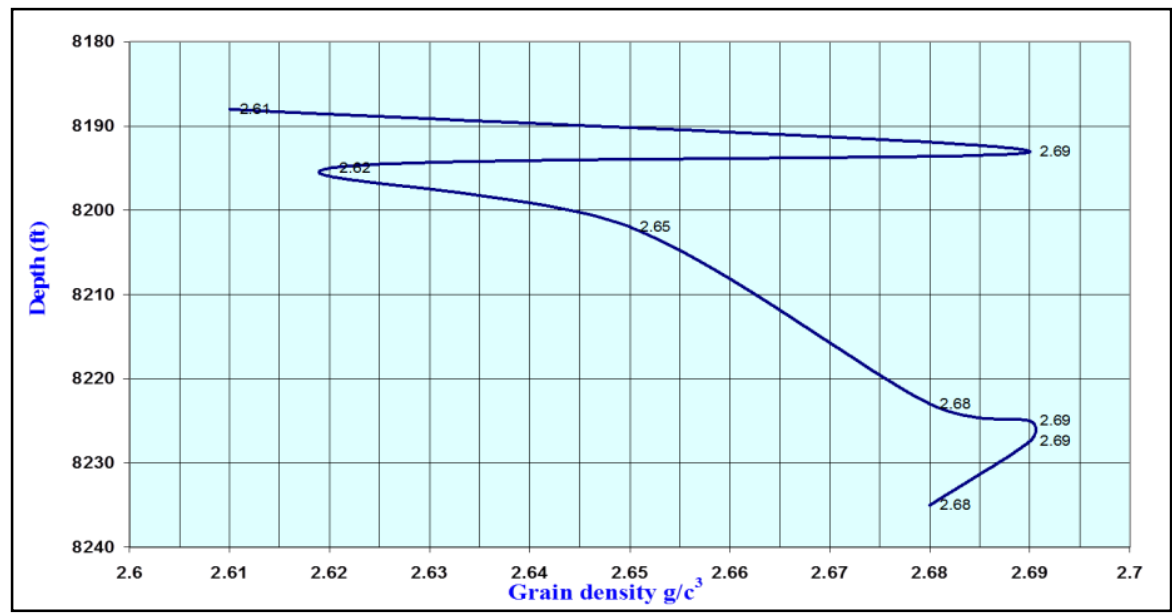

Figure 2: Effect of depth on Grain density for well S2.

Figures 3, 4, show the relation of formation resistivity factor, F, with porosity, $\Phi$ at different pressures for the wells S1, S2.Figures 5 and 6 show the results obtained at ambient conditions and at different overburden pressures for the two wells S1, S2.

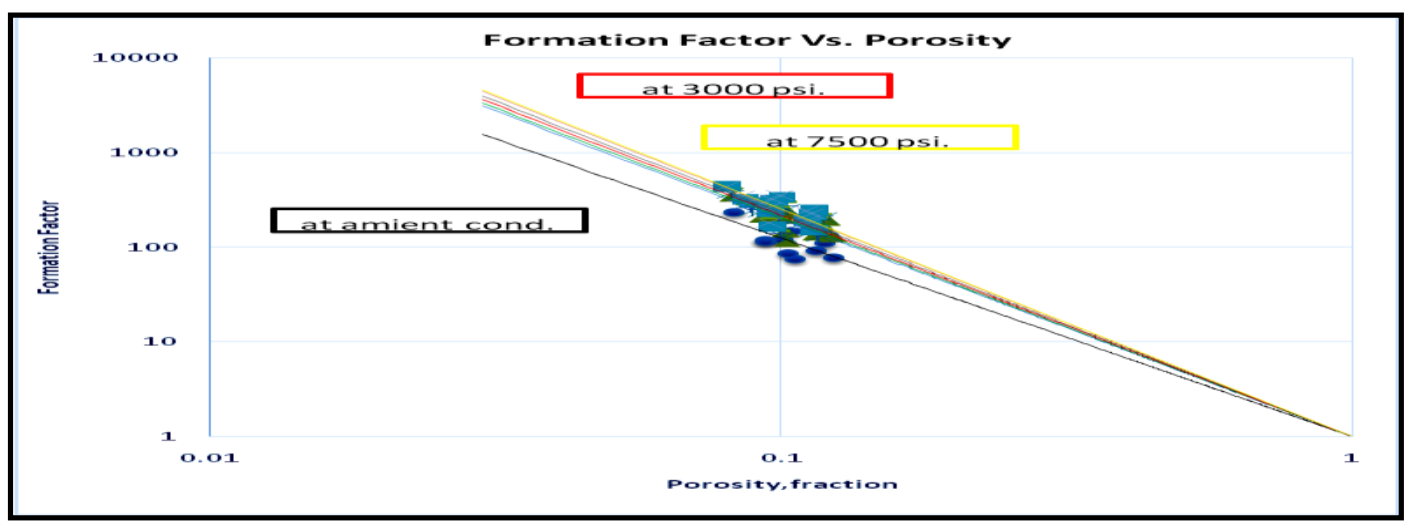

Figure 3: Formation factor Vs. porosity at different pressures for wellS1.

As the pressure is applied to the rock samples, rock resistivity and formation factor increased, while porosity decreased. The figures $(3,4)$ show that:

- For well S1, the cementation factor having the lowest porosity range (8 $12 \%$ ) was 2.09 at ambient conditions, and increased up to 2.4 at 7500 psi. the change was 0.31 .

- In well S2, the porosity range $(10-28 \%)$ in the middle; cementation value was 2.16 at ambient conditions and increased up to 2.26 . The change was 0.10 . 


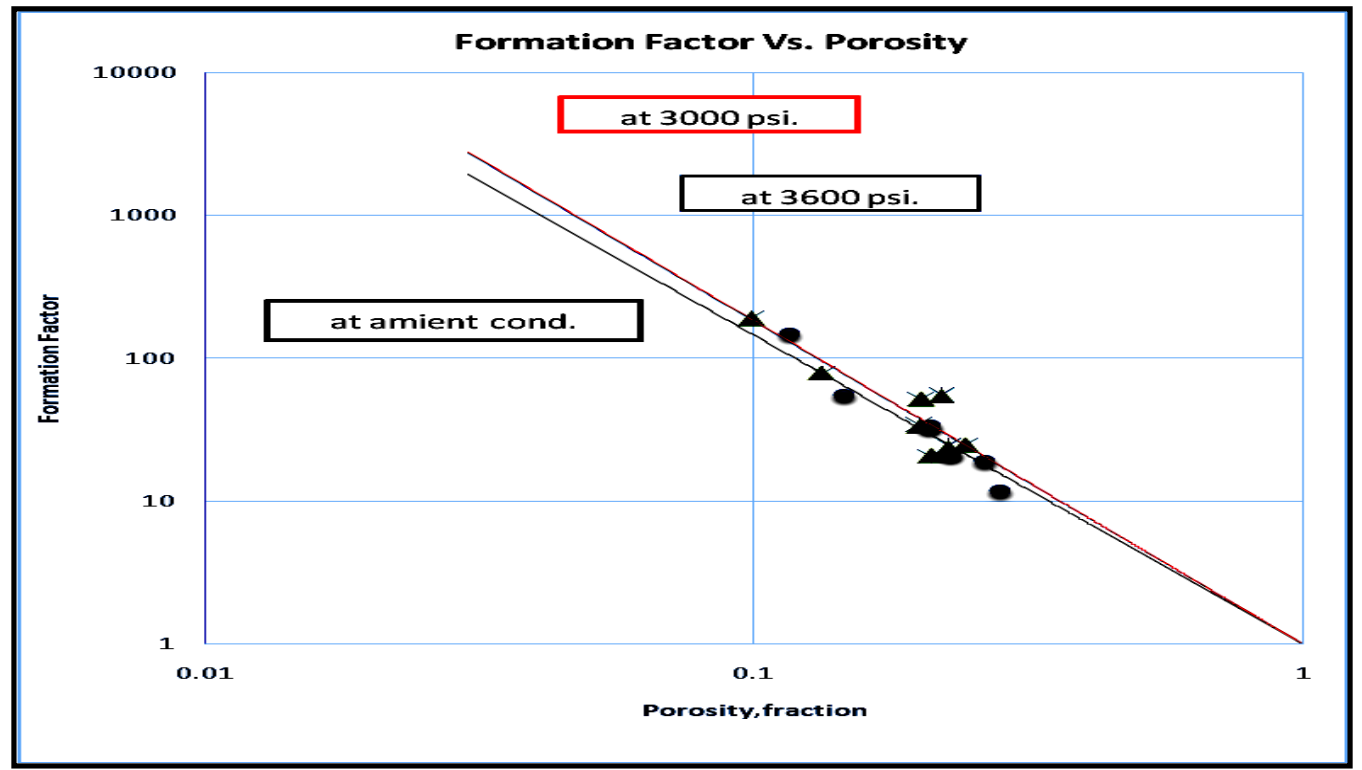

Figure 4: Formation factor Vs. porosity at different pressures for well S2.

It was obvious that the response to overburden pressures was more noticeable in wells that have low porosity values. It is noted that the increase in porosity value will decrease cementation percentage change at overburden pressure. Wells with low porosity values are more changeable in cementation factor than others at the same overburden pressure. The reduction in porosity with increasing pressure differ somewhat from one sample to another to reach $4.9 \%$ for sample 5, nearly $10.4 \%$ for sample 14 , and $9.6 \%$ for sample 29 at 7500Psi. Furthermore the cementation factor's percentage change noted to be the highest (20.14\%) sample 28 at $10.16 \%$ porosity.

\section{Percentage Change Calculations:}

To quantify the change from one value to another percentage change the following relation is used:

Percentage change $=\mathrm{m}($ at overburden pressure $)-\mathrm{m}($ at ambient conditions $) \times 100$

\section{Stress effect on a single sample:}

In order to study the effect of stress on porosity and consequently cementation factor, at a single well, three samples: 5, 14, and 29 were chosen from 30 collected from well S1. Porosity and cementation factor were plotted with stress, Fig. 7, 8. The percentage changes in porosity $\Phi$, and Cementation factor $\mathrm{m}$, at those samples were also calculated in Tables 5-7. 


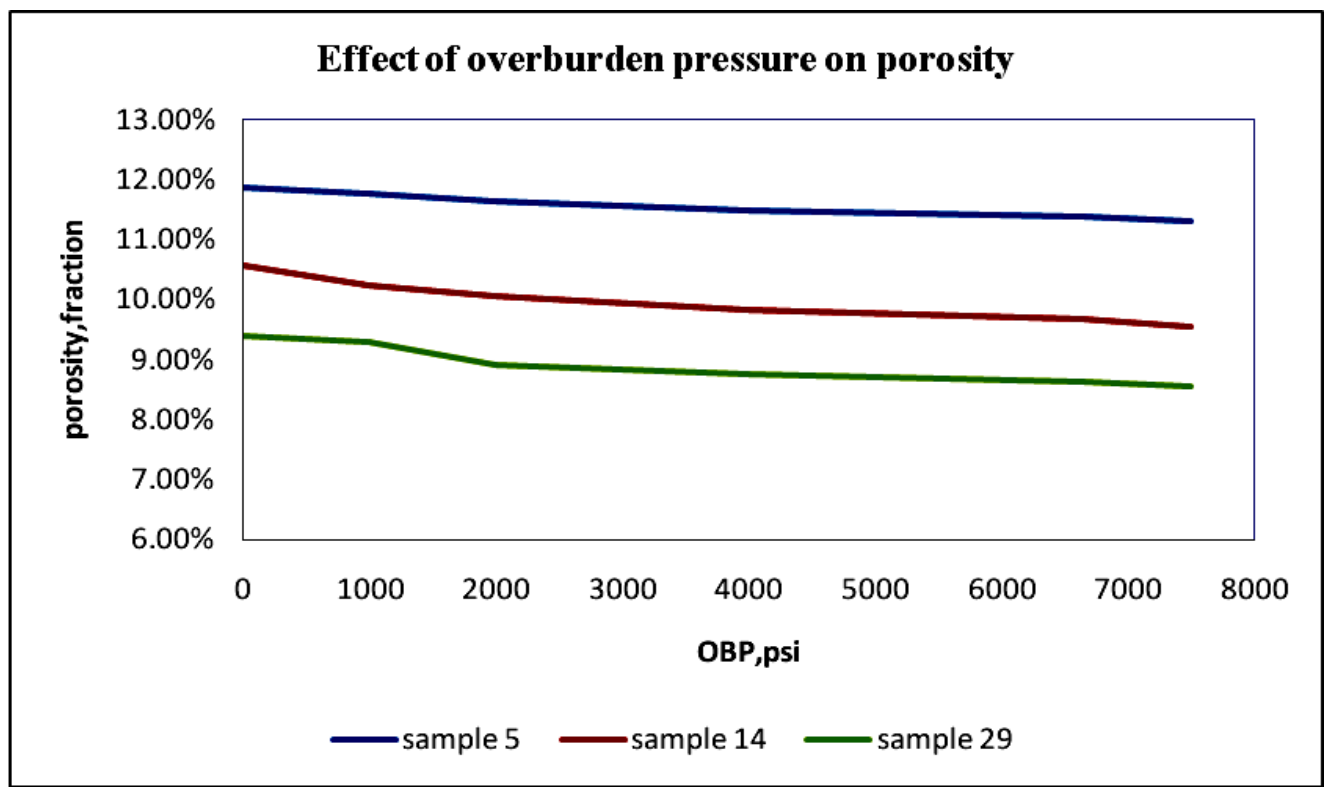

Figure 5: Effect of OBP on porosity for three samples from well S1.

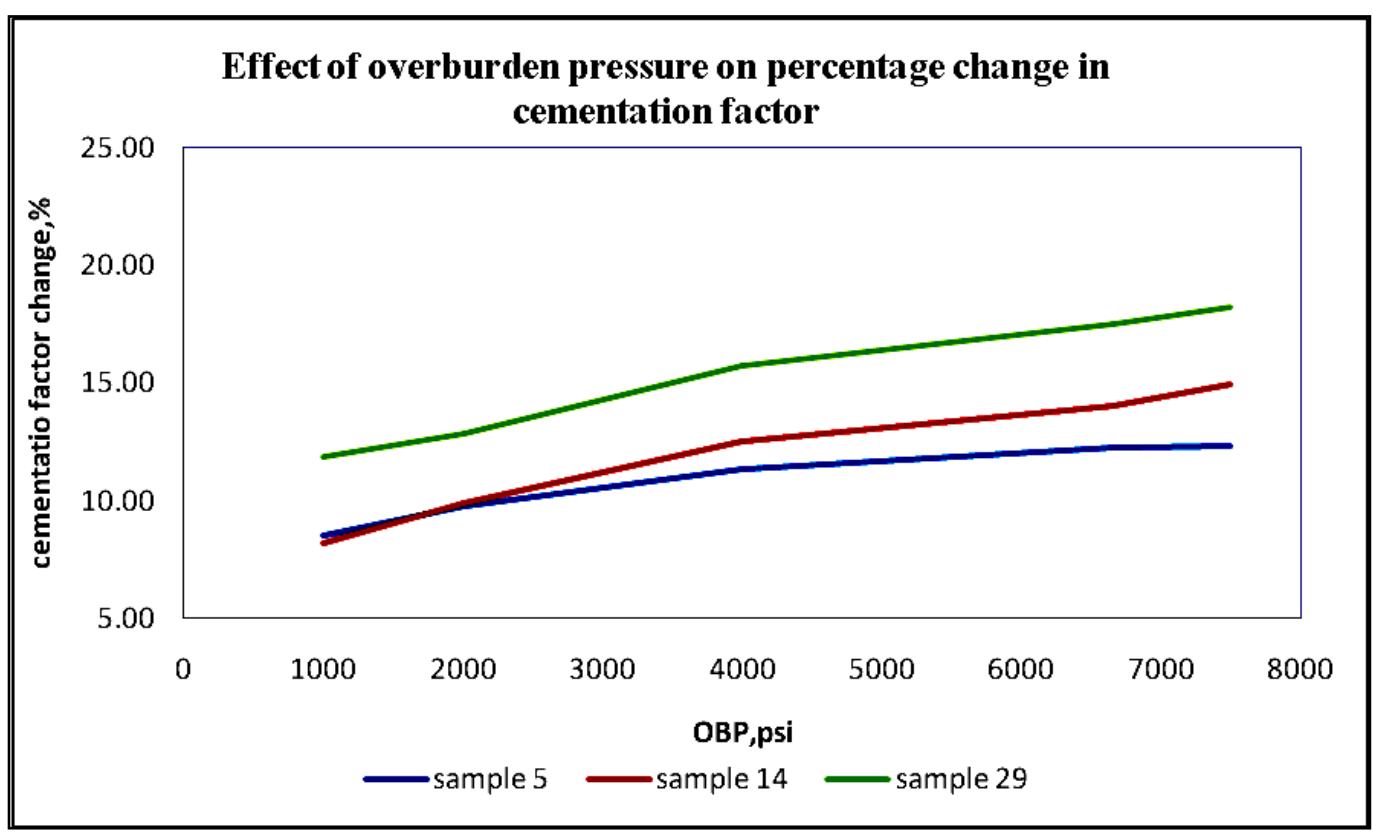

Fig 6: Effect of OBP on cementation factor change for three samples from well S1. 


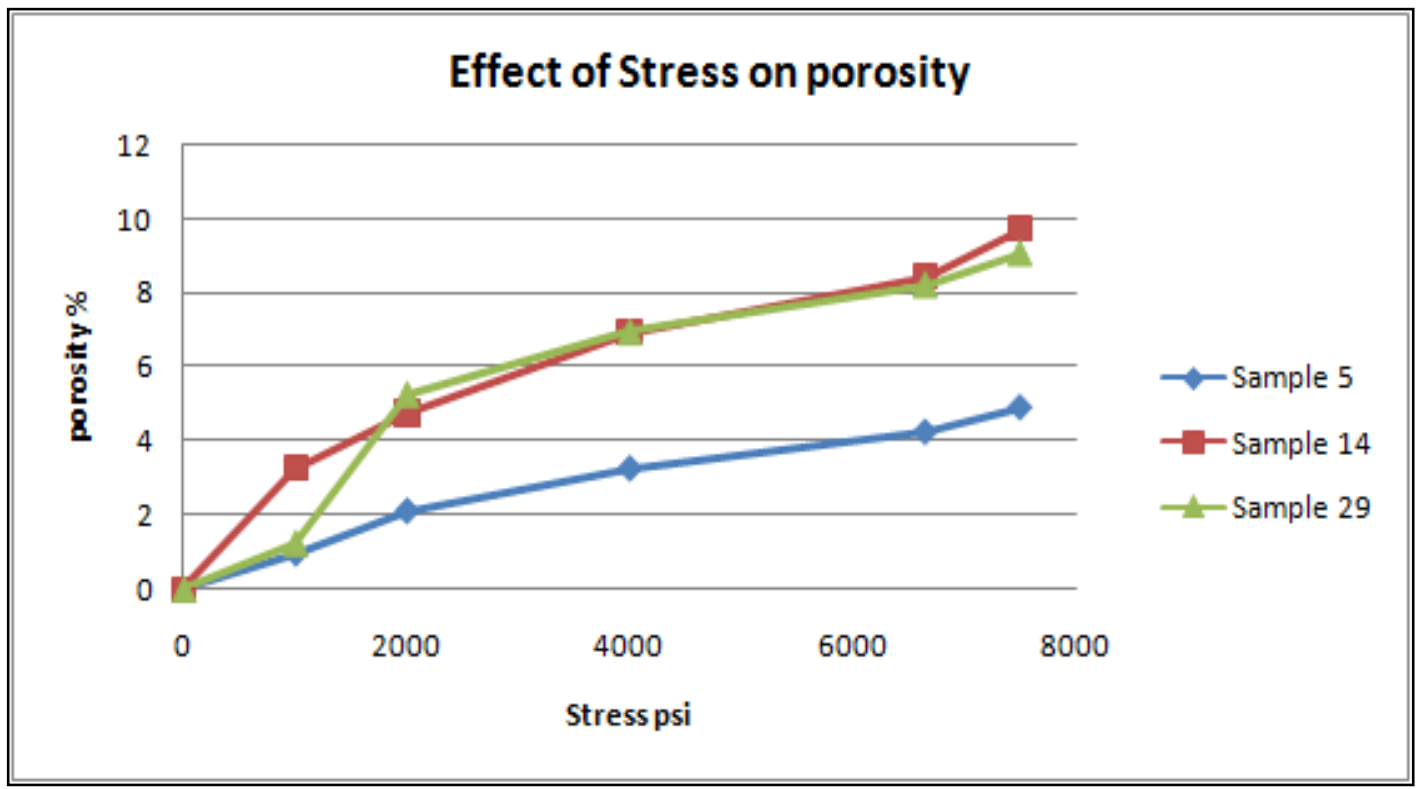

Figure 7: Effect of stress on porosity for three samples from well S1.

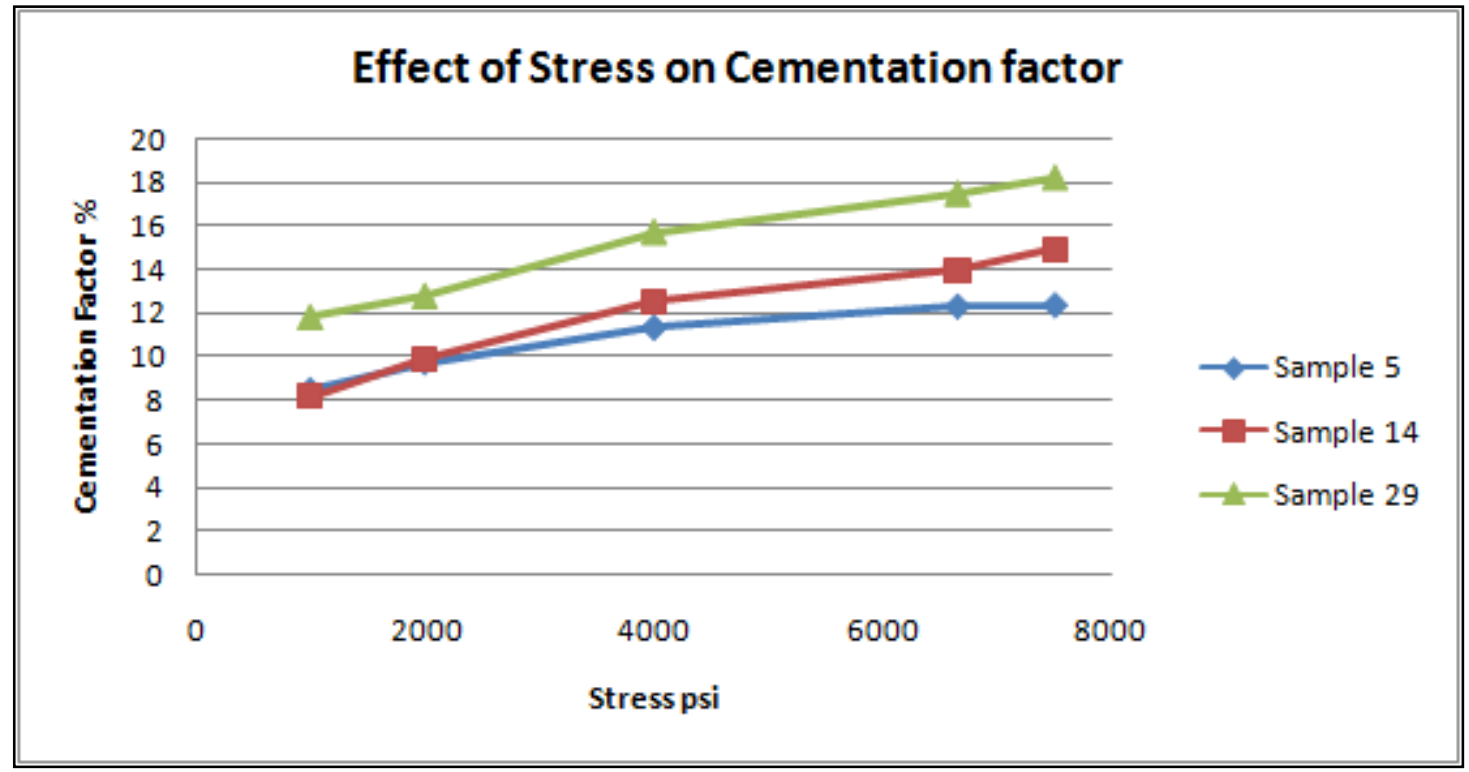

Figure8: Effect of stress on cementation factor change for three samples from well S1.

Table 5:Results of sample 5 from well S1

\begin{tabular}{|c|c|c|c|c|c|}
\hline $\begin{array}{c}\text { Stress } \\
\text { Psi }\end{array}$ & $\begin{array}{c}\text { Porosity } \\
\%\end{array}$ & $\begin{array}{c}\text { Formation } \\
\text { factor }\end{array}$ & $\begin{array}{c}\text { Cementation } \\
\text { factor }\end{array}$ & $\begin{array}{c}\text { Perc. change in } \\
\text { Porosity, } \%\end{array}$ & $\begin{array}{c}\text { Perc. change in } \\
\text { cementation Factor, \% }\end{array}$ \\
\hline 0 & 11.88 & 110.4 & 2.208 & 0.00 & \\
\hline 1000 & 11.76 & 168.6 & 2.396 & 0.97 & 9.50 \\
\hline 2000 & 11.63 & 184.0 & 2.424 & 2.11 & 11.33 \\
\hline 4000 & 11.49 & 204.1 & 2.458 & 3.25 & 9.76 \\
\hline
\end{tabular}




\begin{tabular}{|l|c|c|c|c|c|}
\hline 6650 & 11.38 & 219.1 & 2.479 & 4.23 & 12.29 \\
\hline 7500 & 11.3 & 223.5 & 2.481 & 4.89 & 12.35 \\
\hline
\end{tabular}

Table 6:Results of sample 14 from well S1

\begin{tabular}{|c|c|c|c|c|c|}
\hline Stress & $\begin{array}{c}\text { Porosity, } \\
\%\end{array}$ & $\begin{array}{c}\text { Formation } \\
\text { factor }\end{array}$ & $\begin{array}{c}\text { Cementation } \\
\text { factor }\end{array}$ & $\begin{array}{c}\text { Perc. change in } \\
\text { Porosity, } \%\end{array}$ & $\begin{array}{c}\text { Perc. change in } \\
\text { cementation factor, } \%\end{array}$ \\
\hline 0 & 10.6 & 74.7 & 1.920 & 0.00 & 8.17 \\
\hline 1000 & 10.2 & 113.9 & 2.077 & 3.28 & 9.89 \\
\hline 2000 & 10.1 & 126.9 & 2.110 & 4.75 & 12.53 \\
\hline 4000 & 9.8 & 150.0 & 2.160 & 6.96 & 14.00 \\
\hline 6650 & 9.7 & 165.8 & 2.189 & 8.44 & 14.92 \\
\hline 7500 & 9.5 & 178.4 & 2.206 & 9.74 & \\
\hline
\end{tabular}

Table 7:Results of sample 14 from well S1

\begin{tabular}{|c|c|c|c|c|c|}
\hline Stress & $\begin{array}{c}\text { Porosity, } \\
\%\end{array}$ & $\begin{array}{c}\text { Formation } \\
\text { factor }\end{array}$ & $\begin{array}{c}\text { Cementation } \\
\text { factor }\end{array}$ & $\begin{array}{c}\text { Perc. change in } \\
\text { Porosity, } \%\end{array}$ & $\begin{array}{c}\text { erc. change in cementation } \\
\text { factor, \% }\end{array}$ \\
\hline 0 & 9.4 & 114.5 & 2.005 & 0.00 & 11.87 \\
\hline 1000 & 9.3 & 206.8 & 2.243 & 1.25 & 12.83 \\
\hline 2000 & 8.9 & 237.8 & 2.262 & 5.25 & 15.74 \\
\hline 4000 & 8.7 & 285.4 & 2.321 & 6.94 & 17.48 \\
\hline 6650 & 8.6 & 320.9 & 2.355 & 8.21 & 18.20 \\
\hline 7500 & 8.5 & 340.0 & 2.370 & 9.06 & \\
\hline
\end{tabular}

\section{Stress effect on the two wells:}

On the whole, there was no linear relationship between cementation factor and overburden pressure and the value of cementation factor at a specific pressure cannot be predicted. Table 7 lists the percentages change in cementation factor for the two sandstones.

Table 8: Percentages change in cementation factor

\begin{tabular}{|c|c|c|c|c|}
\hline Well & $\begin{array}{c}\text { Porosity } \\
\text { ranges, } \%\end{array}$ & $\begin{array}{c}\text { Cementation factor } \\
\text { at ambient cond. }\end{array}$ & $\begin{array}{c}\text { Cementation factor } \\
\text { at 3000 Psi }\end{array}$ & $\begin{array}{c}\text { Percentage } \\
\text { change, } \%\end{array}$ \\
\hline S1 & $8-12$ & 2.09 & 2.34 & 11.9 \\
\hline S2 & $12-28$ & 2.16 & 2.25 & 4.17 \\
\hline
\end{tabular}

It is noted that the increase in porosity value will decrease cementation percentage change at certain overburden pressure. Moreover, the mean percentage change in the two sandstones wells at 3000 psi was $8 \%$. The Wells with low porosity values are 
more changeable in cementation factor than the wells of high porosity, at the same overburden pressure.

In a uniformly porous media, conductor brine is occupying all the connected pores; therefore all the pore brine is continuous phase and can conduct electrical current. This phenomenon decreased the length of the conducting paths especially in high porosity samples. After applying overburden pressure, the rock will be compacted, and porosity decreased caused increasing in cementation factor and minimizing in pore volume of the system. In heterogeneous rocks (the pores are non-uniformly). The brine distribution also become non-uniformly distributed in pores media; some pores are isolated and not contributed to current flow. This phenomena makes big different in cementation factor as the stress increase.

\section{Conclusions}

It is not appropriate to apply constant average values for the cementation factor in entire formation or well, because there are several factors affecting this parameter. The following can be concluded:

1. Measuring cementation factor at overburden conditions is important to reduce uncertainties in hydrocarbon estimation.

2. The cementation factor does not change significantly at porosity higher than $10 \%$ at constant stress.

3. The cementation factor of sandstones depends on stress, the magnitude of the dependence related to porosity.

4. The influence of overburden pressure on cementation factor is lower in sandstones samples than in carbonate samples.

5. In sandstone, cementation factor variability appears to be controlled by the inter-particle porosity.

6. The main remaining difficulty is to link the electrical response to the appropriate structural parameters of the rock.

7. The impact of stress on cementation factor is especially important for low porosity rocks.

\section{Recommendations}

It is recommended to:

1. Extend the study by using plug samples with lower porosity values to study the effect of stress extremely.

2. Investigate the effect of stress on cementation factor of sandstone rocks in order to indicate the shrinkage of pore volume and porosity 


\section{References}

- Archie, G.E.; 1942; "The Electrical resistivity Lof as an Aid in Determining Some Reservoir Characteristics"; Trans. AIME.

- Antwan M. Avedisian. (1988). Well Log Analysis. Printed by Al-Mousel University. Iraq

- Amyx, W. A., Daniel M. B., and Robert, L. W.; 1960; "Petroleum Reservoir Engineering"; McGraw-Hill Book Company.

- C. E. Ubani, Y. B.Adeboye, A. B.Oriji; 2012; Advances In Coring And Core Analysis For Reservoir Formation Evaluation; Available online at www.vurup.sk/petroleum-coal Petroleum \& Coal 54 (1) 42-51.

- Ching h. wu; 1992; petroleum engineering 311reservoir petrophysics class notes : department of petroleum engineering texasa\&m university college station, texas.

- Frailey, S. M., Damico, J. \&Leetaru, H. E. (2011). Reservoir characterization of the Mt. Simon Sandstone, Illinois Basin, USA. Energy Procedia 4, 5487-5494.

- Fadhil SarhanKadhim, Ariffin S., Ahmed K.; Researcher 2016; Correlation Between Cementa-tion Factor And Carbonate Reservoir Rock Properties; http://www.sciencepub.net/researcher

- Gomez, C. T., Dvorkin, J. \&Vanorio, T; (2010); Laboratory measurements of porosity, permeability, resistivity, and velocity on Fontainebleau sandstones; Geophysics 75, E191.

- Glover, P. (2009). What is the cementation exponent? A new interpretation. The Leading Edge 28, 82-85.

- Haro, C; (2010); The Equations Archie Forgot: Anisotropy of the Rocks; SPE Reservoir Evaluation \& Engineering 13, 823-836.

- Hilmi S. Salem.(1993). Derivation of The Cementation Factor (Archi's Exponent) And The Kozeny-Carman Constant From Well Log Data, and Their Dependence on Lithology and Other Physical Parameters. SPE, 26309.

- Hector, P., Fernando S., Guadalupe, G., Jesus R., and Carlos V.; (2007); Petrophysical Characterization of Carbonate Naturally fractured Reservoir for Use in Dual Porosity Simulator; SPG-RT-183, Stanford, Calefornea.

- Lucia, F.J. (2007). Carbonate Reservoir Characterization, An Integrated Approach.2nd Edition, Springer, Berlin. 
- Myeres, M. (1991). Pore combination modelling: a technique for modelling the permeability and resistivity properties of the complex pore system. SPE 22662. P7788.

- Medina, C. R., Rupp, J. A. \& Barnes, D. A; (2011); Effects of reduction in porosity and permeability with depth on storage capacity and injectivity in deep saline aquifers: A case study from the Mount Simon Sandstone aquifer; International Journal of Greenhouse Gas Control 5, 146-156.

- Rezaee, M. R., Motiei, H. \&Kazemzadeh, E; (2007); A new method to acquire m exponent and tortuosity factor for microscopically heterogeneous carbonates; Journal of Petroleum Science and Engineering 56, 241-251.

- Schlumberger, (1989). Log Interpretation-Principles/Applications. Eight Printing, Sugar Land, Texas.

- Salem, H. S. \&Chilingarian, G. V. (1999). The cementation factor of Archie's equation for shaly sandstone reservoirs. Journal of Petroleum Science and Engineering 23, 83-93.

- Saeed Rafiee, AbdolnabiHashemi, and Mohammad Shahi; 2014; A New Cementation Factor Correlation in Carbonate Parts of Oil Fields in South-West Iran; Iranian Journal of Oil \& Gas Science and Technology, Vol. 3, No. 2, pp. 01-17.

- WJ Teh, GP Willhite, JH Doveton, JS Tsau ; 2011; Improved Predictions of Porosity from Microresistivity Logs in a Mature Field through Incorporation of Pore Typing; SPE Eastern Regional Meeting held in Columbus, Ohio, USA, 17-19 August. 